\title{
SÔBRE A DISPERSÃO DO TRIATOMA INFESTANS
}

\author{
Mario B. Aragão
}

Foram reunidas as informaçōes disponiveis sôbre a dispersão do $\mathbf{T}$. infestans no Brasil $e$ sôbre o seu comportamento face ao combate com inseticidas nos focos isolados da espécie.

Com base nesses elementos $e$ no que se conhece sôbre os fatôres que regem a dispersão äas espécies invasoras, é discutido o fato do T. infestans ter sido eliminado de quase todos os focos isolados e ter resistido aos dois ensaios melhor conduzidos no Brasil, para a erradicação da espécie em municípios situados dentro de sua área normal de ocorrência.

Finalmente, o autor conclui que, nos focos isoladios, à acão dos inseticidas somou-se a resistência oposta à proliferação da espécie pelas condições do ambiente $e$ que, por isso, as técnicas de erradicação do $\mathrm{T}$. infestans devem ser estuãadas na área onde a dispersão da espécie é contínua.

Nāo é um fenômeno raro a dispersão das espécies invasoras se processar primeiramente de forma contínua até ocupar completamente determinada região, adiante da qual elas só conseguem se estabelecer em pequenas áreas isoladas. Três exemplos dêsse tipo de distribuição estão representados em mapas transcritos no livro de Elton, em 1958 (12), hoje clássico, sôbre a ecologia das invasōes, e com respeito a um dêles, o do fungo Eudothia parasitica, o autor informa oue diversas infecçôes isoladas foram erradicadas.

E, também, um fato relativamente comum os animais mudarem de nicho quando encontram um outro desocupado, estando nesse caso tôdas as espécies ruderais que, certamente, são mais antigas que o homem.

Com base nessas idéias é que será feito o presente estudo sôbre a dispersão do $T$. infestans.

\section{ELABORAÇÃO DOS MAPAS}

A figura 1 é parte de um mapa publicado por Aragão \& Dias em 1956 (3), com algumas modificaçōes baseadas em Usinger, Wigodzinsky \& Rickman (27) e no mapa da figura 2 .

A figura 2 baseia-se nos seguintes autores:

a) - T. infestans

Pernambuco - Dobbin \& Cruz, 1966 (11) ;

Minas Gerais - Pellegrino, 1951 (20);

Goiás - Carvalho \& Verano, 1956 (6), e Galvão, Souza \& Lima, 1967 (15);

Rio de Janeiro - Bustamante \& Gusmão, 1954 (5) e Aragão \& Souza, 1971 (4); São Paulo - Unti \& Silva, 1951 (26) e Silva \& Corrêa, 1954 (25);

Paraná — Lobo, 1959 (17); 
Santa Catarina - Ferreira Neto, Ferreira, Leal \& Martins, 1971 (13);

Rio Grande do Sul - Coutinho, Pinto \& Barbosa, 1952 (7) ;

\section{b) - Areas de colonização recente:}

Goiás - Almeida \& Lima, 1959 (1);

São Paulo - Mombeig, 1952 (19).

Na figura 3 estão superpostos os mapas de distribuição do T. infestans e do T. brasiliensis, publicados por Serebrenick (23).

\section{AS AREAS DE DISPERSÃO}

Na figura 1 vê-se que, atualmente, o $T$. infestans ocupa três áreas de dispersão distintas. Uma delas está isolada pela Cordilheira dos Andes e as outras duas estão separadas por uma zona onde as condições climáticas são adversas à espécie (3).

Usinger, Wigodzinsky \& Rickman, em 1968 (27) acreditam que, provàvelmente, a espécie passou a ocupar domicilios humanos nos vales interandinos da Bolívia, ainda nos tempos pré-colombianos. Em seguida a essa transição dos buracos de roedores para aquelas moradias parecidas com as tocas dêsses animais, a espécie se dispersou para onde "as condições microclimáticas da habitação humana são parecidas com as existentes nos buracos de roedores dos vales interandinos relativamente frescos e áridos, da Bolivia."

Como tem sido mostrado por diversos autores, a temperatura amena e a secura do ar parecem ser as únicas exigências da espécie. Por outro lado, a natureza dos obstáculos que separam essas três áreas

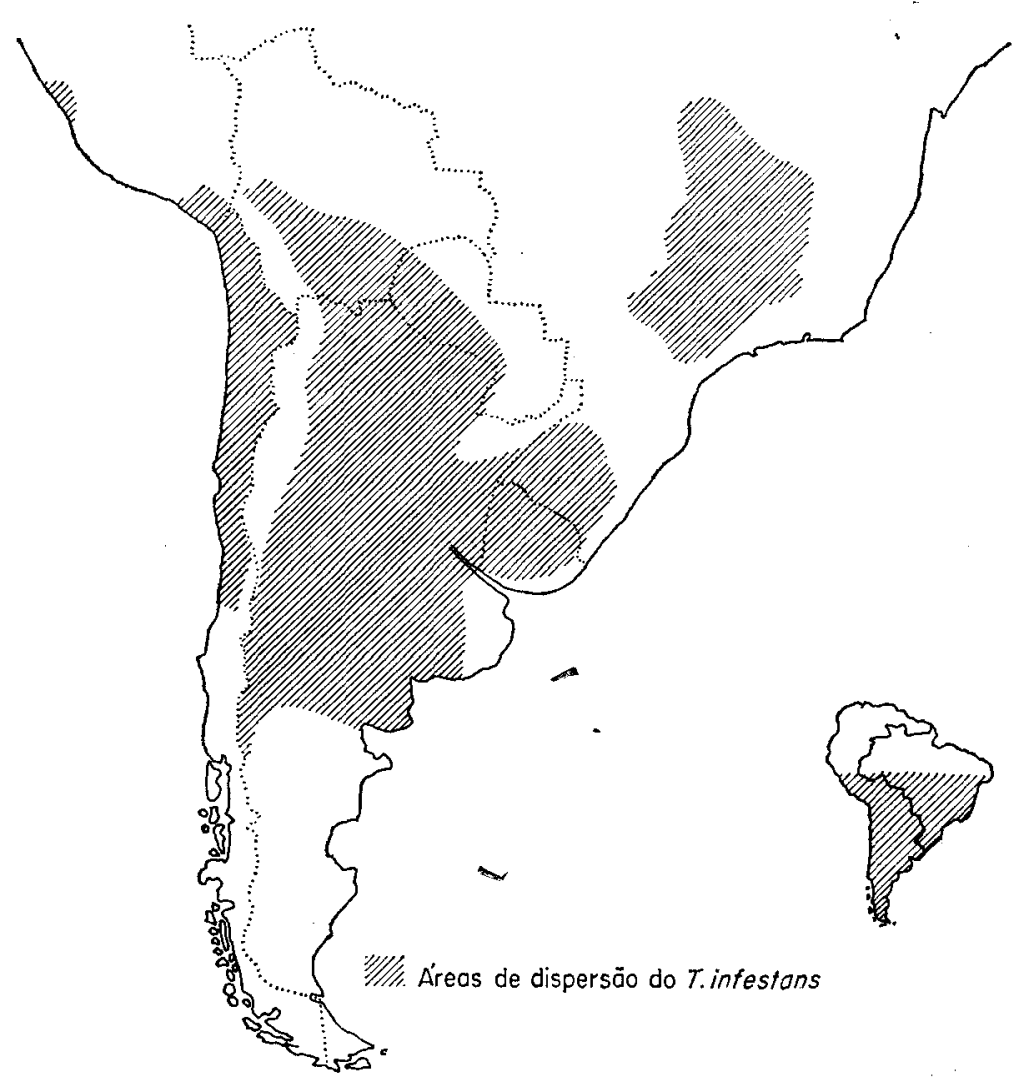

Figura 1 - Dispersão do Triatoma infestans na América do Sul. 
assinaladas na figura 1 deixa claro que a sua dispersāo foi feita através do transporte pelo homem. Os Andes são terciários e, portanto, muito anteriores à ocupação do continente pelo homem e, na área centro-sul brasileira, o $T$. infestans se dispersou depois da introdução dos tipos de moradia vindos com as culturas africana e européia. Até o Rio Grande do Sul a espécie viria sem dificuldade, pois aí a sua área de dispersão é contínua até a Bolivia. Do Rio Grande do Sul para São Paulo e Minas Geraís, a distância é grande, porém deve-se considerar que, durante o ciclo do ouro, houve um tráfico intenso de tropas de muares entre o Rio Grande do Sul e as áreas de mineraçāo, localizadas principalmente no Estado de Minas Gerais. As zonas mais recentementa colonizadas foram as primitivamente ocupadas por florestas, que só passaram a despertar maior interêsse com o advento do ciclo do café. No mapa da figura 2 estão assinaladas as áreas que, em 1930, ainda estavam cobertas por matas primárias e, portanto, onde a espécie se dispersou nos últimos 40 anos.

Esse mapa da figura 2 parece mostrar que a área de dispersão da espécie, no Brasil, está estabiliżada, uma vez que o seu transporte no meio de cargas ou pertences de viajantes sòmente tem propiciado a sua instalação em pequenas áreas isoladas.

\section{OS FOCOS ISOLADOS}

A primeira referência ao encontro de $T$. infestans em um foco isolado é a de Lent, em 1942 (16), que classificou exemplares provenientes da fronteira do Estado do Rio de Janeiro com São Paulo, sem chamar a atenção, entretanto, para o fato do inseto estar vivendo fora da área normal de ocorrência. Esse foco do Vale do $\mathrm{Pa}$ raiba foi posteriormente estudado por Bustamante \& Gusmão (5), do lado do Estado do Rio de Janeiro, e por Unti \& Silva (16), do lado de São Paulo, e eliminado por êsses mesmos pesquisadores, com aplicações de BHC.

Na mesma época Pellegrino (20) coletou em Contagem, no Estado de Minas Gerais, alguns milhares de $T$. infestans e um número inferior a uma dezena em mais 6 localidades situadas fora da área de dispersão da espécie. Ao que parece, sòmente em Contagem a espécie havia formado colônias e, logo em seguida, Pellegrino \& Brener (21) eliminaram o foco.

Diversas referências imprecisas sôbre o foco do oeste do Estado de Santa Catarina estão citadas por Ferreira Neto, Ferreira, Leal \& Martins (13). Esses autores, que fizeram as pesquisas na área, relatam que em 1954 foram encontrados $T$. infestans colonizando em domicílios dos municípios de Cunhaporã, Palmitos e São Miguel do Oeste e que, uma busca posterior feita em 1958, não logrou encontrar a espécie em Palmitos e em São Miguel do Oeste. Informam êsses pesquisadores que os próprios moradores eliminaram o inseto, aplicando, nas casas, inseticidas de uso agrícola à base de BHC. Em Cunhaporã, entretanto, persistia a infestação dos domicílios.

Em Pernambuco, Dobbin \& Cruz, em 1966 (11) assinalaram $T$. infestans em três municípios vizinhos, Cumaru, Riacho das Almas e Surubim e, segundo James Dobbin (Comunicação pessoal), a espécie desapareceu com as campanhas rotineiras de borrifação com BHC.

Mais recentemente Aragão \& Souza, em 1971 (4) encontraram, numa área muito pobre do Município de Duque de Caxias, no Estado do Rio de Janeiro, o $T$. infestans colonizando domicílios. Uma parte dessa área fol borrifada com BHC, em dezembro de 1970, sendo portanto cedo para aferir resultados.

\section{DISCUSSÃO}

Para que uma espécie colonize uma área é necessário que os seguintes requisitos estejam satisfeitos:

1 - Que as condições de ambiente sejam adequadas;

2 - que existam nichos que ela possi ocupar;

3 - que não encontre resistência para a ocupação dêsses nichos.

Os dois primeiros requisitos são óbvios. o primeiro, entretanto, pode estar próximo do limite e permitir que a espécie viva durante um certo número de anos em que as condiçôes clímáticas se mantêm próximas das normais. Sôbre êsse ponto, o café, no sul do Brasil, oferece um exemplo típico; vegeta normalmente até que haja um ano 


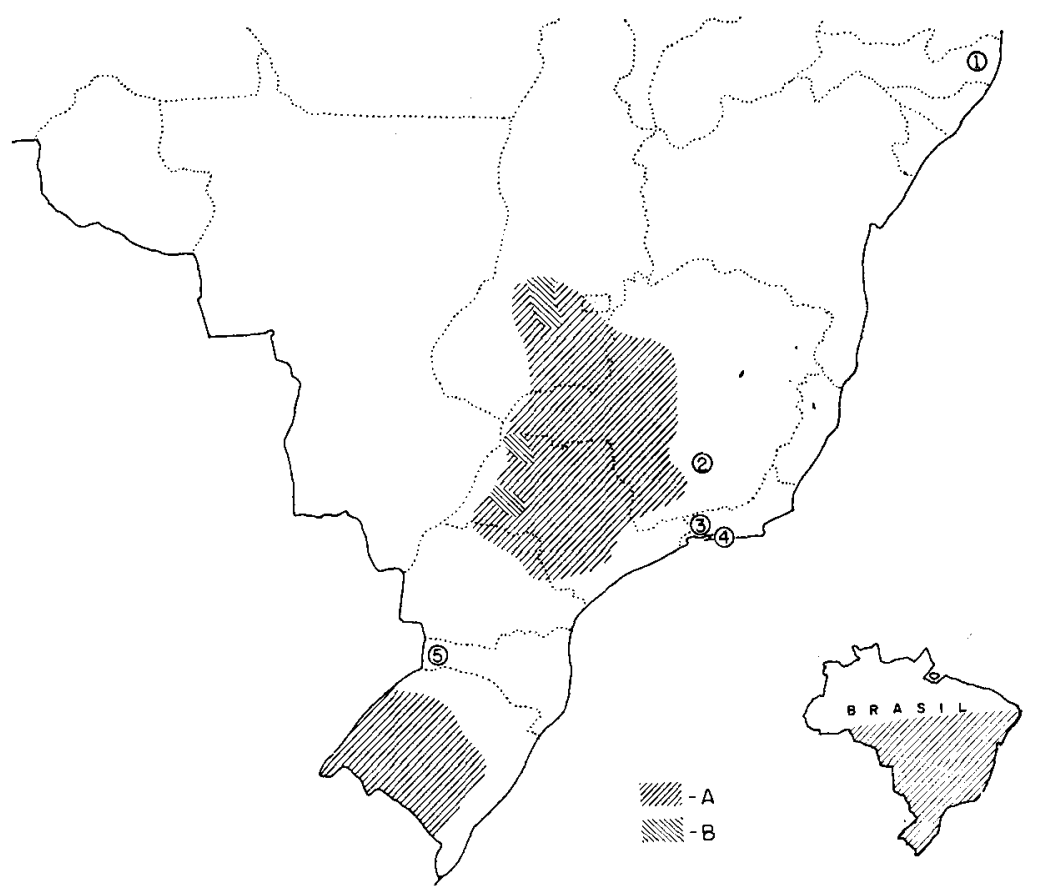

Flgura 2 - Dispersáo do Triatoma infestans no Brasil.

Areas contínuas de dispersáo: a) - Area colonizada antes de 1930 b) - Area colonizada depois de 1930.

Focos isolados: 1 - Municípios de Cumaru, Rlacho das Almas e Surubim, em Pernambuco; 2 - Muntcipio de Contagem (Cldade Industrial) em Minas Gerais; 3 - Municíptos de Areias e Queluz, em São Paulo, e Rezende e Itaverá, no Estado do Rio de Janeiro; 4 - Mun1cíplos de Caxlas e Nova Iguaçu, no Estado do Rlo de Janeiro; Municípios de Cunhaporá, Palmitos e São Miguel do Oeste, em Santa Catarina. 
mais frio, em que as geadas liquidam a lavoura.

Um exemplo, muito conhecido, do encontro de resistência para a ocupação do nicho é observado na dispersão do pinheiro do Paraná (Araucaria angustifolia). Esta espécie, quando cultivada nos solos férteis da encosta do sul do Brasil, desenvolve-se melhor do que no planalto. No entanto, a sua área de distribuição natural termina bruscamente na borda do planalto, onde os solos melhoram e passam a ser ocupados pela mata latifoliada.

o comportamento dos ratos ruderais nas zonas de mata e de caatinga também esclarecem o assunto. Nessas últimas, a substituição da vegetação naturalmente escassa pelas lavouras pouco altera a faúna local que, no caso da floresta, é liquidada com a derrubada e exposição do terreno. O que se observa, então? Nas caatingas, um pequeno número de ratos ruderais, restritos à casa e ao perí-domicílio, e, nas lavouras das zonas florestais, imensas populaçōes dêsses roedores exóticos vivendo, às vêzes, bem longe das habitações.

No caso dos triatomíneos parece haver uma concorrência pelo nicho entre o Triatoma infestans e o Panstrongylus megistus e, em algumas áreas, também com 1o T. sordida. E que sugerem as contagens de triatomíneos feitas nas localidades onde tem sido tentada a erradicação dêsses insetos $(8,9,10,14)$ e é também o que se infere de duas tabelas publicadas por Silva et alii. (24) onde se nota que o número de $P$. megistus e de $T$. sordida, capturados pela Saúde Pública do Estado de São Paulo, vem aumentando desde $o$ ano de 1951.

Nos dados fornecidos pelos dois primeiros autores citados, sôbre o acompanhamento dos ensaios de erradicação dos triatomíneos, observa-se que, ao mesmo tempo em que as capturas de $T$. infestans cairam dràsticamente, o número de $P$. megistus coletados variou pouco ou aumentou. Não resta dúvida que essa última espécie existe, em estado silvestre, nas duas áreas e, portanto, poderia ter recolonizado as habitações. Por que, entretanto, os seus exemplares eram minoria antes da aplicação do inseticida? Tudo indica que isso se deve ao fato do $T$. infestans estar melhor adaptado para ocupar o nicho domiciliário.

Dentre as outras interaçōes biológicas, os grandes predadores (homem e animais domésticos) não devem desempenhar papel importante. Se fôssem eficientes em matar os barbeiros, que os sugam, todos os cães e gatos da zona chagásica estariam infectados pelo Trypanosoma cruzi, pois mastigam êsses insetos. Dos pequenos predadores, sòmente as formigas são eficientes, chegando mesmo a evitar a colonização de uma área da Venezuela pelo Rhodnìus prolixus [Gomez-Nuñes, in Aragão \& Souza (4) ]. Com respeito ao $T$. infestans não existem observações feitas em condições naturais, porém nos arredores do Rio de Janeiro as formigas criam problemas para a manutenção de colônias artificiais (22). Dentre os parasitas dos triatomíneos, só se conhece o Telenomus fariai, que nunca foi devidamente estudado, e o capítulo dos microrganismos está em branco.

Onde existe um elemento de sugestão muito forte com respeito ao papel dos inimigos naturais, na dispersão dos triatomíneos, é no fato de sua dispersão em direção ao litoral do Brasil Sudeste ser demarcada por linhas do relêvo que delimita determinadas condições de umidade (2). Tudo indica que existem espécies restritas ao litoral e à encosta que impedem que êsses insetos colonizem nos domicílios.

O único elemento climático que parece estar atuando, isoladamente, é a temperatura. A figura 3, onde estão superpostos os mapas de distribuição do $T$. infestans e do $T$. brasiliensis, no vale do São Francisco, publicados por Serebrenick (23), parece mostrar que, se o $T$. infestans não se dispersou para a área mais quente do norte, não foi por questão de inimigo natural, caso contrário o $T$. brasiliensis e o $T$. maculata (não assinalado no mapa) não poderiam colonizar os domicílios do baixo vale.

Essa demarcação das áreas de dispersão do $T$. infestans por condições bem caracterizadas de temperatura e umidade, se choca com os achados, cada vez mais freqüentes, de focos de infestação distantes e em zonas onde as condições climáticas são as mais diversas. claro que uma espécie de ampla distribuição, como o $T$. infestans, deve dispor de grande variabilidade genética. Por outro lado, o seu transporte no meio de pertences humanos não deve ser raro, como atestam as diversas citaçōes do encontro de exemplares de $T$. infestans no Nordeste, reunidas por Lu- 


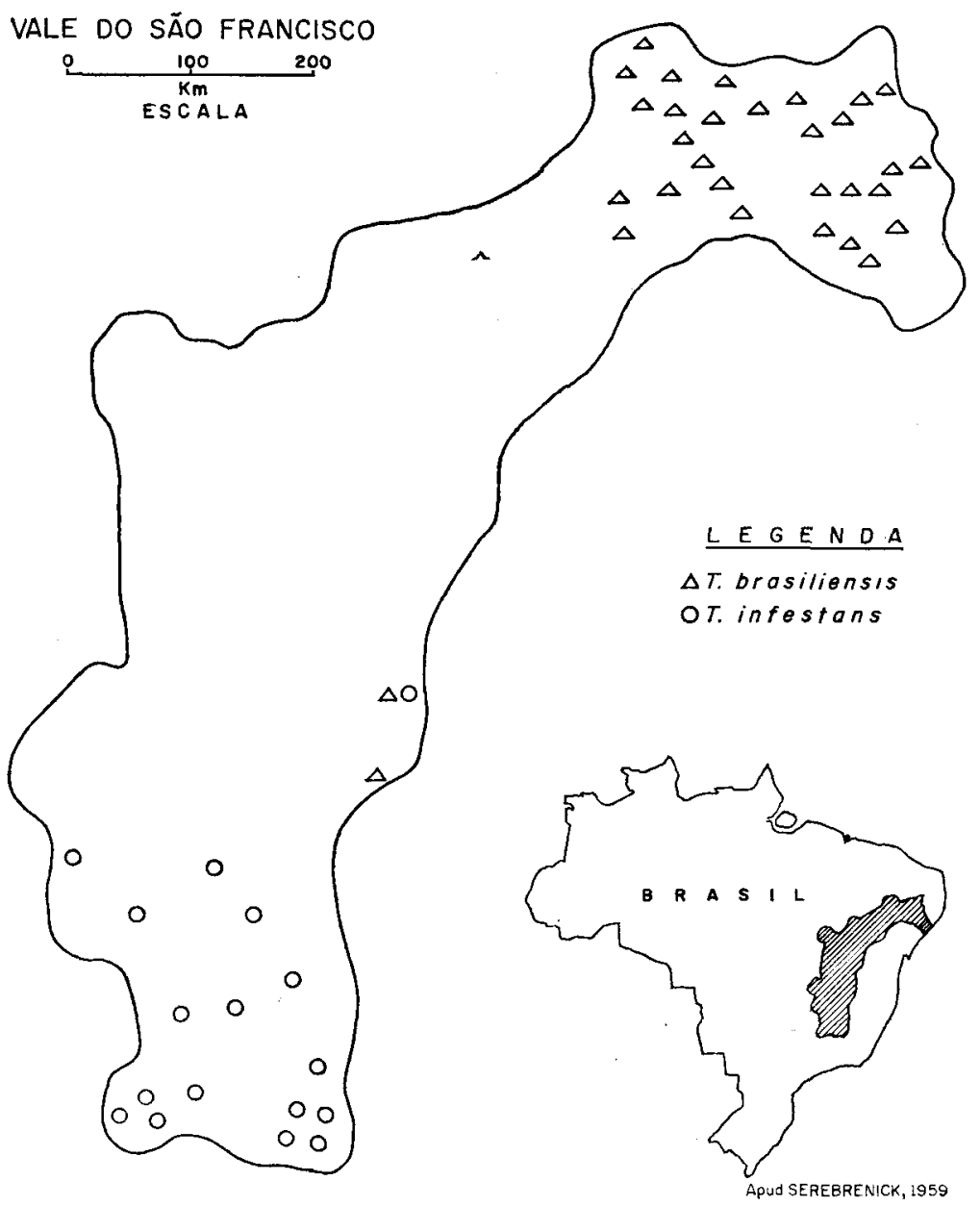

Figura 3 - Localidades do Vale do São Francisco onde foram assinalados Triatoma brasiliensis e $T$. infestans. 
cena, em 1970 (18). Além disso, as criações de laboratório mostram que as ninfas não são muito susceptiveis às condições climáticas adversas. Uma vez realizadas algumas posturas, o problema se resumiria aos insetos atingirem a fase adulta numa época do ano favorável. Entretanto, apesar dêsses argumentos, essa discordância entre os dois grupos de fatos, áreas bem delimitadas e focos isolados, parece que vem sendo esclarecida com os resultados obtidos em algumas tentativas de erradicação do inseto.

Essas tentativas de erradicação do $\boldsymbol{T}$. infestans, no Brasil, podem ser divididas em dois grupos, as que foram realizadas dentro da área de dispersão da espécie e as levadas a efeito em focos isolados. Das primeiras, duas foram feitas por pesquisadores do mais alto gabarito, os Profs. Pedreira de Freitas e Emanuel Dias (14) Em ambas os resultados foram ótimos, não chegando, porém, a erradicar $o$ inseto. Por outro lado, em quase todos os focos isolados o $T$. infestans tem sido erradicado o que se tem conseguido com diversos métodos de combate. No Vale do Paraíba, do lado do Estado do Rio de Janeiro, Bustamante \& Gusmão em 1954 (5), planejaram e executaram uma técnica destinada a conseguir a erradicação. No mesmo vale, do lado de São Paulo, Unti \& Silva (26) utilizaram a rotina normal de combate aos triatomíneos. Em Pernambuco, também foi a rotina de aplicação de BHC que extinguiu o foco (Comunicação pessoal de James Dobbin). Em Minas Gerais, Pellegrino \& Brener (21) também não tiveram dificuldade em eliminar o foco de Contagem. Em Santa Catarina, sem nenhuma colaboração de entidades oficiais, os próprios moradores liquidaram o inseto em
Palmitos e em São Miguel do Oeste. (13). Com respeito ao combate, com êxito, ao $T$. infestans pelos próprios moradores, há referências de Coutinho, Pinto \& Barbosa, em 1952 (7), na periferia da área de distribuição da espécie no Rio Grande do Sul, e de Aragão \& Souza (4) nos arredores do Rio de Janeiro, nenhuma delas, entretanto, observadas pessoalmente pelos próprios pesquisadores. Poder-se-ia alegar que a espécie estava ocupando a área há pouco tempo e, portanto, ainda não estava bem adaptada. Esse argumento não parece prevalecer porquanto, nas áreas de colonização recente, assinaladas no mapa da figura 2, o inseto se mantém até hoje, apesar de já ter sido combatido pelas borrifações rotineiras de $\mathrm{BHC}$. O que parece ser mais lógico é que, nesses focos isolados, o $T$. infestans já estava encontrando uma certa resistência, seja devido às condições adversas do ambiente físico, seja devido à presença de inimigos naturais e que essa resistência, somada à ação do inseticida, tornou-se suficiente para erradicar a espécie. Deve-se ainda referir que uma onda excepcionalmente forte de calor, que assolou o Rio de Janeiro em janeiro e fevereiro de 1971, liquidou, quase completamente, as colonias de $T$. infestans que são mantjdas há cêrca de 30 anos no Instituto Oswaldo Cruz. A própria colônia originária do foco isolado do Município de Duque de Caxias, situada a cêrca de $30 \mathrm{Km}$ do Instituto e, também ao nível do mar, ficou reduzida a uma meia dúzia de exemplares.

Dêsses fatos parece ser lícito tirar uma conclusão de caráter prático. É a de que qualquer técnica de erradicação de triatomíneos deve ser desenvolvida dentro da área normal de dispersão da espécie visada.

\section{SUMMARY}

All available information was gathered about the dispersion of $\mathbf{T}$. infestans in Brazil and about its behavior when the species were combated with insecticiaies in isolatea foci.

Based on these elements and on what is known about factors which rule the dispersion of the invading spesies, it is debatable whether $\mathrm{T}$. infestans was eliminated from almost all isolated foci and to have resisted two of the best conducted trials in Brazil for the erraaication of the species in places situated within the area of their normal occurence.

The author concludes that, in isolated foci, the action of the insecticide was added to the resistance offered to the proliferation of the species by the en- 
vironmental condition and that, because of this, the erradication techniques against $\mathbf{T}$. infestans should be developed in areas where the dispersion of the species is continuous.

\section{BIBLIOGRAFIA}

1) ALMEIDA, F. F. M. \& LIMA, M. A. - Planalto Centro-Ocidental e Planalto Mato-Grossense. Conselho $\mathrm{Na-}$ cional de Geografia, Rio de Janeiro, 1959 .

2) ARAGÃO, M. B. - Aspectos climáticos da doença de Chagas. II. Área de ocorrência do Panstronylus megistus (Burmeister, 1835). Rev. Bras. Malar. D. Trop., 13: 171-93, 1961.

3) ARAGÃO, M. B. \& DIAS, E. - Aspectos climáticos da doença de Chagas. I. Considerações sôbre a distribuição geográfica do Triatoma infestans. Rev. Bras. Malar. D. Trop, 8: 633-41, 1956.

4) ARAGÃO, M. B. \& SOUZA, S. A. Triatoma infestans colonizando em domicilios da Baixada Flumiinense, Estado do Rio de Janeiro, Brasil. Rev. Soc. Bras. Med. Trop., 5: 1971.

5) BUSTAMANTE, F. M. \& GUSMÃO, J. B. - Sôbre a possibilidade de erradicação do Triatoma infestans com duas ou três aplicações domiciliares de BHC. Resultados de uma prova de campo. Rev. Bras. Malar. D. Trop., 6: $101-13,1954$.

6) CARVALHO, A. G. \& VERANO, O. T. - Epidemiologia e profilaxia da doença de Chagas em Goiás. Rev. Goiana Med., 2: 241-78, 1956.

7) COUTINHO, P. P., PINTO O. S. \& BARBOSA, J, A. - Contribuição ao conhecimento dos triatomíneos domiciliares e de seus indices de infecção pelo Schizotrypanum cruzi no Estado do Rio Grande do Sul, Brasil. Rev. Bras. Malar. D. Trop., 4: 211-26, 1952.

8) DIAS, J. C. P. - Reinfestação do Município de Bambuí, MG, por triatomineos transmissores da doença de Chagas. Mem. Inst. Oswaldo Cruz, 63: 107-19, 1965 .

9) DIAS, J. C. P. - Reinfestação do Município de Bambui por triatomíneos transmissores da doença de Chagas (2. a nota). - Mem. Inst. Oswaldo Cruz. 66: 197-208, 1968.
10) DIAS, E. \& DIAS, J. C. P. - Variações mensais da incidência das formas evolutivas do Triatoma infestans e do Panstrongylus megistus no $\mathrm{Mu}-$ nicípio de Bambuí, Estado de Minas Gerais (II ${ }^{\mathrm{a}}$ Nota: 1951 a 1964). Mem. Inst. Oswaldo Cruz, 66: 209-26, 1968.

11) DOBBIN Jr., J. E. \& CRUZ, A. E. Alguns informes sôbre triatomíneos de Pernambuco. Rev. Bras. Malar. D. Trop. 18: 26i-79, 1966.

12) ELTON, C. S. - The ecology of invasions by animals and plants. Methuen and Co. Ltd., London, 1958.

13) FERREIRA NETO, J. A. FERREIRA, M. O., LEAL, H. \& MARTINS, C. M. - Novos dados sôbre os triatomineos do Estado de Santa Catarina, Brasil. Rev. Soc. Bras. Med. Trop., 5: 1971.

14) FREITAS, I. L. P. - Profilaxia da moléstia de Chagas. In Daença de Chagas, pp. 541-59, editado por J. Romeu Cançado. Imprensa Oficial do Estado de Minas Gerais, Belo Horizonte, 1968 .

15) Galvão, A. B.. SOUZA, H. A. S. \& LIMA, R. R. - Espécies de Triatominae ocorrentes em Goiás e descrição de uma nova espécie. Rev. Bras. Malar. D. Trop. 19: 397-412, 1967.

16) LENT, H. - Transmissores da moléstia de Chagas no Estado do Rio de Janeiro. Rev. Fluminense Med, 7: 151-61, 1942 .

17) LOBO, A. G. S. - Contribuição ao conhecimento da distribuição geográfica dos triatomíneos domiciliares e seus indices de infecção natural pelo S. cruzi no Estado do Paraná. Rev. Bras. Malar. D. Trop., 11: 539-72, 1959 .

18) LUCENA, D. T. - Estudo sôbre a doenca de Chagas no nordeste do Brasil. Rev. Bras. Malar. D. Trop. 22: 3-173, 1970.

19) MOMBEIG, P. - Pionniers et planteurs de Sắo Paulo. Librairie Armand Colin, Paris, 1952. 
20) PELLEGRINO, J. - Transmissores da doença de Chagas no Estado de Minas Gerais. Rev. Assoc. Med, Minas Gerais 2: 43-46, 1951 .

21) PELLEGRINO, J. \& BRENER, Z. Profilaxia de um foco de doença de Chagas nas proximidades de Belo Horizonte (Cidade Industrial) Rev. Assoc. Med. Minas Gerais, 2: 233-50, 1951 .

22) PERLOWAGORA - SZUMLEWICZ, A. - A eficácia do expurgo domiciliário com hexaclorociclohexana no contrôle do vetor da doença de Chagas (a importância de algumas características biológicas dos triatomíneos no planejamento do ciclo de aplicação do inseticida) . Rev. Bras. Malar. D. Trop., 6: 63-100, 1954.

23) SEREBRENICK, S. - Distribution géographique des triatomidées dans la vallée du São Francisco et ses rapports avec les conditions climatiques. An.
Inst. Med. Trop. 16 supl. 7 pp. 133$49,1959$.

24) SILVA, E. O. R., DIAS JUNIOR, J. \& GUARITA, O. F. - Suspensão do rociado no combate ao Triatoma infestans em áreas do Estado de São Paulo, Brasil. Rev. Saúde públ., S. Paulo, 3: 173-81, 1969.

25) SILVA, T. L. \& CORREA, R. R. Informes atuais sôbre a distribuição geográfica dos triatomíneos na área paulista (Hemiptera, Reducidiae). Folia Clin. et Biol. 22: 79-84, 1954.

26) UNTI, O. \& SILVA, T. L. - Moléstia de Chagas no Vale do Paraíba, Estado de São Paulo. Nota sôbre a profilaxia e epidemiologia. Arq. Hig. Saúde Públ., 16: 131-138, 1951.

27) USINGER, R. L., WYGODZINSKY, P. \& RYCKMAN, R. E. - The biosystematics of triatominae. Ann. Rev. Entomol. 11: 309-30, 1966. 